\title{
A GEOGRAFiA CULTURAL POR PAUL CLAVAL
}

\author{
EDUARDO BRITO HENRIQUES ${ }^{1}$
}

Num sinal bem expressivo da actual reabilitação da geografia cultural, visível em diversas comunidades geográficas, foi publicada em 1995 uma interessante e útil obra em língua francesa sobre a matéria, da autoria de Paul CLAVAL2

Poucos nomes estão tão estreitamente associados ao processo (bem sucedido) de reanimação dos estudos culturais na geografia francesa quanto o deste notável geógrafo da Universidade de Paris-Sorbonne. Responsável por um centro de investigação especificamente destinado aos temas da geografia cultural e da etnogeografia - o Laboratoire Espace et Culture, P. Claval ficou ainda ligado à criação, já nos anos 90, de uma revista trimestral inteiramente dedicada à mesma temática (Géographie et Cultures), facto que não pode deixar de ser considerado um gesto ousado. Não causa portanto surpresa que tenha sido este autor a produzir a obra em análise, concebida como um compêndio ou um livro de introdução às grandes temáticas da geografia cultural.

La Géographie Culturelle está organizado em quatro partes, que agrupam catorze capítulos num total de quase 400 páginas (incluindo a extensa bibliografia com mais de 500 referências).

A primeira parte - a mais curta - é consagrada à história e teoria da geografia cultural. Cobrindo os principais períodos da evolução do pensamento nesta área disciplinar, fornece uma síntese actualizada das diversas sensibilidades geradas ao longo do tempo no seio da geografia cultural, com referência inclusivamente às actuais tendências da chamada new cultural geography. É todavia na análise que faz da geografia cultural alemã do final do século XIX, muito fértil mas a respeito da qual se dipõe em regra de escassa informação, que reside a maior utilidade desta parte da obra.

A segunda parte do livro trata das relações entre a cultura e a vida social. Numa linguagem clara e acessível, P. Claval analisa aspectos como o modo de transmissão dos conhecimentos e das regras de conduta, o papel mediador da

\footnotetext{
1 Assistente da Faculdade de Letras da Universidade de Lisboa. Investigador do Centro de Estudos Geográficos da Universidade de Lisboa. Centro de Estudos Geográficos, Faculdade de Letras, Cidade Universitária, 1699 LISBOA Codex. Fax: (351-1)793 86 90; E-mail: ceg@ mail.telepac.pt.

2 Claval, P. (1995) - La Géographie Culturelle. Ed. Nathan, Paris.
} 
cultura na relação do indivíduo com a sociedade e as articulações entre cultura e poder. A opção por uma exposição simples e sucinta destes tópicos de reflexão, própria de um livro concebido como síntese, leva o autor a evitar certos quadros teóricos provavelmente tidos como menos ortodoxos, limitando-se às teorizações mais clássicas. Teria sido interessante analisar, a respeito das relações entre cultura e poder, por exemplo, as teses de A. Gramsci e em particular os conceitos de hegemonia e resistência, muito úteis para o entendimento das dinâmicas da cultura e do papel que nelas desempenham as subculturas ${ }^{3}$. Em todo o caso, dentro do registo "clássico" preferido nesta obra, resulta particularmente interessante o capítulo referente às relações entre culturas (Cap. 7), no qual P. Claval procura interpretar, na melhor tradição geográfica, o processo de formação de áreas culturais recorrendo à teoria da difusão de inovações de T. Hägerstrand.

A terceira parte do livro aborda as relações entre a cultura, o meio e a paisagem. Nas primeiras páginas analisam-se, em moldes que recordam os trabalhos da geografia humanista, as atitudes do indivíduo face ao espaço geográfico, cobrindo-se desde as questões relacionadas com os mecanismos da orientação espacial aos princípios da territorialidade humana, sempre ricamente ilustradas com exemplos retirados dos mais variados contextos culturais (dos esquimós às comunidades rurais do Vietname, dos índios da América do Norte à sociedade japonesa tradicional).

Seguidamente, ainda na terceira parte do livro, é retomada uma das temáticas mais caras à geografia cultural clássica, e também mais recorrentes nos trabalhos que foram sendo produzidos, ora na óptica culturalista, ora na óptica possibilista, até às décadas de 50 e 60: a mediação da tecnologia, vista como sinal ou concretização das várias culturas, na relação dos grupos humanos com o ambiente, na formação das paisagens e na organização do espaço. Ao retomar estas questões, $\mathrm{P}$. Claval introduz porém, de forma dispersa, elementos inovadores, tanto ao nível das perspectivas de análise como dos conteúdos analisados, facto que vem enriquecer consideravelmente o texto. É de realçar como exemplo disso o interessante e original capítulo que o autor dedica à história e geografia da alimentação (Cap. 10).

A última parte da obra, que consideramos a mais atractiva, intitula-se "Uma geo-história das culturas". Na tradição de F. Braudel - e desenvolvendo ideias já anteriormente apresentadas em outros trabalhos seus - P. Claval apresenta uma interpretação teórica da evolução das civilizações (sistematizada num esquema que designa por transição cultural). Procurando fornecer uma leitura de conjunto para as transformações operadas na repartição mundial das áreas culturais ao longo da história, detém-se em particular na análise dos processos de modernização e de ocidentalização. A obra termina com um capítulo onde se afloram alguns dos grandes desafios culturais do mundo contemporâneo, como o papel dos media no contexto actual de crescente globalização, a pós-modernidade e a crise de valores que lhe está associada, o renascimento dos nacionalismos ou o fundamentalismo

3 V., a este respeito, JACKSON, P. (1989) - Maps of Meaning. An Introduction to Cultural Geography. Routledge, Londres. 
muçulmano.

La Géographie Culturelle de P. Claval, revelando embora em certos aspectos uma concepção demasiada "elástica" da geografia cultural, o que não é de estranhar num autor com experiência e obra publicada em temas geográficos muito variados, constitui um trabalho de referência na geografia cultural de língua francesa. Concebida como compêndio, a obra privilegia o tratamento extensivo das matérias abordadas em detrimento de análises mais detalhadas ou incisivas. É por isso um livro especialmente indicado e muito útil para todos quantos inciam o estudo nesta área disciplinar, ou que sobre ela pretendem estar informados. 